\title{
LEISURE AND THE OBLIGATION OF SELF-WORK: An Examination of the Fitness Field
}

\author{
Jennifer Smith Maguire \\ Citation: \\ 2008. Leisure and the Obligation of Self-Work: An Examination of the Fitness Field. \\ Leisure Studies. 27(1): 59-75.
}

\begin{abstract}
:
This article examines the cultural field of fitness as a network of producers, consumers, products and practices that has developed around the care of the body through physical exercise. Drawing on a thematic text analysis of US exercise manuals, the paper focuses on how the commercial fitness field naturalizes associations between physical exercise and leisure, and between leisure and selfwork. In particular, the analysis examines three themes and their relevance to our broader understanding of leisure in contemporary consumer society: the management of leisure time; the use of leisure for self-investment strategies; and the promotion of consumption as the framework for leisure and an accompanying notion of pleasure. The fitness field casts light on how leisure more generally is constructed as a sphere of obligations to make productive use of one's time, to improve one's body and self, and to do so through the wares of the consumer marketplace. The cultural imaginary of leisure as a time of freedom from work and responsibility is thus recast, in an age of individualization, as a time of freedom to accomplish the work of self-production.
\end{abstract}

\section{Keywords:}

body, consumption, individualization, pleasure, self-investment, time

\section{Introduction}

Long-term processes associated with modernity, globalization and postindustrialization have posed challenges to traditional, collective structures of meaning, identity, and regulation, leading some to characterize the contemporary age as one of individualization and reflexive self-production (see, among others, Bauman, 2000, 2004; Beck \& Beck-Gernsheim, 2002; Giddens, 1991). As the balance in identity construction shifts from ascribed categories to achieved projects, the individual is faced with the problem of carrying out self-work. But where does one start in making oneself? Unlike the psyche, the body, 'our first and most unconditional possession' (Simmel, 1950: p. 344), is immediately available for inspection, augmentation, and refinement. The body's prominence in consumer culture stems, in large part, from this connection to the problem of identity: the body is the consumer object (Baudrillard, 1998), the ultimate site for the production and display of the self. As a form of capital necessary to belong and compete in a culture and economy of images and impressions, the body must be decorated, improved, 
managed, and displayed. Working on the body is such an imperative because it is a form of capital (Baudrillard, 1998; Bourdieu, 1984, 1986); one can compete without a well-tended body, but one's chances of success are considerably diminished. In short, the body is a site of work, and work on the body is also, fundamentally, self-work.

One particularly visible mode of self-work in contemporary consumer cultures is fitness, typically defined as purposive physical exercise within the context of leisure. Time use surveys (Gershuny, 2000) and market research (Mintel, 2006), for example, both employ a 'residual' definition of leisure (Haworth \& Lewis, 2005) to categorize fitness and sport activities, meaning that fitness activities are considered leisure because of their occurrence during an individual's 'free' time- the time left over after paid and unpaid labour, over which the individual has perceived control. However, defining fitness as leisure is not uncomplicated, for at least two reasons: first, the residual definition of leisure posits a boundary between work and leisure that appears to be increasingly porous (e.g. Lewis, 2003; Baxter \& Kroll-Smith, 2005); and second, the hard work of exercise and its associated overtones of moral obligation (White, et al., 1995) do not fit easily with the cultural imaginary, or popular notion, of leisure as a time of freedom from obligation and productivity.

The cultural imaginary of leisure has ideological implications: the imaginary 'is that image or representation of reality which masks the historical and material conditions of life' (Ingraham, 1994: p. 203). The concept refers to a way of thinking about leisure that naturalizes the difference between work and leisure as one that is complete, unchanging, and unquestioned. Resting on this opposition are a host of policies and programmes - past and present — concerning the role of leisure as compensation and recuperation for work. While this stark separation may not apply in all lived definitions or experiences of leisure (e.g. Chaplin, 1999; Esteve, et al., 1999), it is regularly invoked in consumer culture, the reproduction of which rests on discretionary income from the world of work being spent in the world of leisureconsumer spending making up approximately 70 percent of the United States' Gross Domestic Product (Swann, 2006) - rather than being saved or reinvested (as in earlier stages of capitalism; Weber, 1992). Both the residual definition and the cultural imaginary of leisure rest on the separation of work and leisure. Sociologists of leisure (amongst others) have challenged the taken-for-granted mutual opposition of work and leisure, calling our attention to the spectrum of activities and continuities of dispositions that fall between and across the two realms, and to the historical specificity of the work/leisure boundary, which must be understood in the context of the dominant political-economic and social order (e.g. Bramham, 2002; Elias \& Dunning, 1986; Parker, 1976; Rojek, 1985, 1989a, 1989b, 1995).

Fitness is a fruitful lens through which to examine the character and meaning of leisure and its contested relationship with work. This article focuses on how, within the commercial fitness field, associations between physical exercise and leisure and, in turn, between leisure and self-work are presented as natural and commonsensical, rather than historically specific and arbitrary. The discussion proceeds with an overview of fitness as a cultural field (Bourdieu, 1993), and a brief examination of the health club industry as one aspect of the naturalization of fitness as leisure. Drawing from a thematic text analysis of a sample of popular US exercise manuals, the article then examines three themes and their relevance to our broader understanding of 
leisure in contemporary consumer society: the management of leisure time; the use of leisure for self-investment strategies; and the role of consumption in framing leisure and an attendant notion of pleasure. It is important to underline, here, that this is an examination not of the lived experience of fitness as leisure, but of its ideal construction through field texts, which may 'act as grids for the perception and evaluation of things' (Foucault, 1991: p. 81). The fitness field and its texts thus serve as windows onto the cultural production of leisure as a sphere of obligations to make productive use of one's time, to improve one's body and self, and to do so through the wares of the consumer marketplace.

\section{The Fitness Field and Leisure}

This article is drawn from the findings of a larger research project (Smith Maguire, 2008) on the commercial culture of fitness in the US that examined the interconnections between commercial fitness clubs, fitness media (including exercise manuals, fitness magazines, and specialist personal trainer publications), and fitness producers (including health club managers and personal trainers). Since the 1970s, a progression of exercise fads and fashions have emerged from increasingly sophisticated and lucrative fitness industries in consumer societies all over the world, but most notably within the US. In 2000, for example, the US sporting goods industry (which includes sports equipment, clothing and footwear) was worth 47.3 billion US dollars (Euromonitor, 2001), while consumer spending on sporting goods in the United Kingdom came to just under 4 billion British pounds, or roughly 7 billion US dollars (Mintel, 2004). Similarly, by 2002 the US had over 22,000 commercial health clubs, more than the number in Germany, Italy, Spain, France and the United Kingdom combined. ${ }^{1}$

Fitness, however, is more than simply a consumer industry, just as physical exercise has long been about more than just bodily vigour and endurance. In the US, physical fitness has been wed to a variety of larger causes, such as moral reform in the nineteenth century Muscular Christianity movement, national strength in Theodore Roosevelt's Strenuous Living philosophy at the turn of the twentieth century, and personal improvement and enjoyment in the burgeoning service economy of the early twentieth century (Green, 1986; Mrozek, 1989). With the exception of times of war, the meaning of fitness over the twentieth century was predominantly cast in terms of individual — rather than social-improvement, and since the 1970s the concept of fitness has increasingly narrowed to a commercialized lifestyle, an individualized project of self-improvement to be carried out in one's leisure time, through the consumption of exercise programs and fitness goods (Smith Maguire, 2008). While goals may vary for specific exercises, the fitness lifestyle is represented as a general enhancement of health, appearance, and, ultimately, quality of life (Howell \& Ingham, 2001). As such, the research from which this article is drawn conceptualizes fitness not as a commercial industry but as a commercial cultural field (Bourdieu 1984, 1993; Ferguson, 1998; Laberge \& Kay, 2002): a network of sites, texts, producers, and consumers that generates practices of exercise and meanings of the exercised body. The commercial fitness field's effect is to 
naturalize the association of exercise with leisure, thereby signalling its relative autonomy from other exercise-related fields.

Commercial health clubs are key sites in the construction of fitness as leisure in the US, claiming 52 percent of all health club members. ${ }^{2}$ Commercial health clubs market themselves as leisure businesses and thus define themselves in opposition to other, competing sites and institutions, such as the YMCA, which promotes physical fitness as an ethical mode of character building; school physical education, which utilizes fitness training as a means of instilling qualities deemed valuable by the labour market; physical therapy centres, which subsume exercise within a broader body of medical-therapeutic expertise; and corporate fitness programs, which endorse exercise as a means of ensuring productivity (Defrance \& Pociello, 1993; Hargreaves, 1986). As such, fitness is constructed in the terms set by the wider commercial leisure field, which include issues of service, convenience and entertainment.

For example, in 1987, the director of the International Health Racquet and Sportsclub Association (IHRSA) discussed the state of the health club industry in the trade journal Athletic Business:

[The] industry is, and is becoming even more so, a convenience industry. ...Managed recreation is a repeat business, and any repeat business industry is a convenience industry. ...In 1985, for the first time in decades, the average American employee began working more than 40 hours per week. ... This time famine is both an opportunity and a limitation for the industry. It's an opportunity because clubs now have the real possibility of generating more money from amenity services than they do from their core membership services. (McCarthy, 1987: p. 42)

The amenity services to which the author refers included dry-cleaning, banking and child-care - in short, converting the health club from a multi-use exercise facility into a multi-purpose leisure and lifestyle facility. Such thinking reflected a general business strategy, informed by market research, which had since the early 1970s taken an interest in the 'convenience-oriented customer' (Anderson, 1971). The issue of convenience is especially pressing for the commercial fitness field's core consumers: the professional/managerial class. ${ }^{3}$ Despite statistics that show an overall decline in working hours (e.g. nVision, 2005), the professional/managerial class has experienced an increase in their typical working week (Jacobs \& Gerson, 1998; Lewis, 2003; Zuzanek et al., 1998), thus constraining the amount of discretionary time available for activities such as the use of a health club. The high economic and cultural capital of the professional/managerial class, coupled with constrained temporal capital, makes convenience a key selling point for leisure services.

Besides service and convenience, the commercial construction of fitness is also shaped by the emphasis on entertainment in the wider consumer leisure industries. For example, in a CNN interview, the owner of Crunch, a New York-based chain of health clubs, makes explicit that he understands his competition in terms of the options his members have for spending their leisure time:

[W] think that people are working longer hours under more stress in their life, both men and women in equal numbers. And we think that, you know, you're no longer getting out of work at 5 or 5:30 but are now working till 6 or 8 o'clock at night. And some people are working on the weekends. And Crunch feels that it's 
competing with Blockbuster. It's competing with movie chains, with theme restaurants and bars and restaurants. And we think that when you're out of work at 7:30 or 8 o'clock at night, we think that we can eliminate stress in your life and entertain you through some of the things that we do. And it's-our competition is other forms of entertainment. (Morris, 1997: no page)

In competition for consumers' discretionary time and income, health clubs thus add entertainment value to fitness activities; for example, piped-in music, televisions, and novel exercise classes are all standard club features. Unlike many other leisure activities, however, health clubs also have added value thanks to endorsements from the health field, as when the US Surgeon General and World Health Organization promote regular exercise as essential for a healthy lifestyle and the reduction of risk for certain diseases. Added leisure values of fun, entertainment and immediacy (Harris, 2005) are not only instrumental in the competition between health clubs and other leisure businesses, but they also signal the commercial field's relative autonomy from the health and political fields that lend it support. Commercial health clubs may benefit from the promotion of exercise in other fields, but they attempt to set the criteria by which they are judged in terms of what they can deliver: not health (as that relies on the individual consumer), but service, convenience and entertainment.

To put this in a broader perspective, commercial health clubs are shaped by the four trends shaping contemporary leisure more generally (Rojek, 1985: pp. 19-23). First, clubs are an element of the privatization of leisure: exercise is constructed as an activity for one's private time and - through fee-based club membership - a semiprivate space. Second, the mode of fitness presented in health clubs is an expression of the individuation of leisure: even in the context of group classes, the work out is typically performed by individual participants with minimal collective interaction, and all eyes trained on the instructor (not unlike the organization of the television or film audience). Third, clubs exemplify the commercialization of leisure, which increasingly requires entry fees, specialized equipment and ancillary guidebooks and services; indeed, commercial health clubs outnumber non-profit YMCAs in the US by 11 to $1 .{ }^{4}$ Finally, health clubs are also manifestations of the long-term pacification of leisure, the equipment in health clubs replacing - and at times mimicking - the brute exertion and physical hardship of manual labour, within the safe confines of a leisuretime work out.

\section{Exercise Manuals and Fitness as Leisure}

Like the health club industry, fitness publishing has been central in the naturalization of fitness as leisure (cf. Smith Maguire, 2002, 2006). Specialized texts such as exercise manuals are crucial 'institutionally constituted points of entry' (Jenkins, 1992: p. 85) for the fitness field. Such texts make vicarious participation possible (that is, reading about fitness without necessarily working out), as well as facilitating more involved participation (that is, applying an educational attitude to fitness activities). Fitness texts - like lifestyle media (Bell \& Hollows, 2005), selfhelp literature (McGee, 2005) and service journalism (Eide \& Knight, 1999) -

provide readers/viewers with both the problems and solutions of everyday life, and in so doing provide lessons in both the specific activities of the field and the overall 
mentality required of individuals to carry out competent self-production. In the case of exercise manuals, the lessons intended for the reader pertain not only to fitness, but to leisure and self-work more broadly: first, the management of leisure time; second, the use of leisure for self-investment strategies; and third, the promotion of consumption, accompanied by a specific notion of pleasure, as the framework for fitness and, more broadly, leisure.

These three lessons or themes emerged from a thematic text analysis of a nonprobability purposive sample of thirteen US exercise manuals. The sample was chosen to reflect a number of dimensions shaping the fitness field: in particular, orientation (manuals with a health-education focus, and those more explicitly linked to commercial fitness); but also gender (manuals targeted directly at women, at men, and at both); class (by and large manuals are a middle class product, but some are more explicitly directed at the professional/managerial class); links to other lifestyle media (manuals published by fitness magazines); and changes over time (between manuals from different decades, and different editions of the same manual). ${ }^{5}$ Sampling for diversity aims at including a range of perspectives, rather than identifying the typical perspective; the point is not to provide a definitive statement on the average content of all exercise manuals, but to compare different perspectives within the same context - a goal to which thematic text analysis is particularly well suited (King, 2004: p. 257).

Thematic analysis is a means of encoding qualitative data that uses a priori themes (based on one's research questions and relevant literature) to organize the data, but which also involves an ongoing refinement of the themes; given the combination of deductive and inductive coding, the final template of themes is likely to have moved beyond the initial themes (Boyatzis, 1998; Fereday \& Muir-Cochrane, 2006; King, 2004). As such, thematic analysis is different from, but not unrelated to, the Grounded Theory approach (Glaser \& Strauss, 1967): the thematic analyst arrives at the data with an outline of what he or she is looking for, but through memos (thoughts that arise in the course of coding that may or may not emerge as a repeated pattern in the data) and comparison between data sources, new themes will emerge from the data, and pre-existing themes will be revised or removed (King, 2004).

Analysis of the exercise manuals began with immersion: reading and re-reading, making notes on, and making copies of the table of contents, introductory chapters, and selected chapter content. The initial note-making, as with the more comprehensive manual coding that followed, was guided by themes derived from the larger project's research questions and cultural field framework, which included issues of authority, status, and problematization (and, as such, the final template and analysis include more than the three themes discussed in this article; see Smith Maguire, 2008). The a priori template was also in part derived from the manuals themselves, using a preliminary analysis of the tables of contents to identify repeated themes used to structure the content of the books. The educational aim of the exercise manuals makes them relatively structured texts (as opposed to, for example, an exerciser's diary entries), and facilitates a more flexible, less structured thematic text analysis (Hogenraad et al., 2003; King, 2004). 
From the analysis of the exercise manuals, three themes emerged that are of particular relevance to an understanding of leisure, related to time, self-investment, and consumption. These are discussed in detail below.

\section{Leisure and Time Management}

The cultural imaginary of leisure implies a separation from work - a time of choice and freedom to do as one pleases; a time unencumbered by the need to be productive. While the separation of leisure and work is increasingly blurry in the post-industrial context, time remains a significant marker. For example, Lewis' (2003) research on accountants suggests that when white-collar workers define extra hours at work as a choice and source of enjoyment, it is the fact that they have chosen to use their time in this way that signifies an element of leisure, despite still being in the physical space of work. In exercise manuals, the association between exercise and leisure is accomplished through a demarcation of time, but as the discussion below illustrates, this construction of fitness as leisure inserts discipline and a productive logic into the realm of 'free time.'

Fitness activities are not the only form of activity vying for consumers' and, especially, professional/managerial consumers', leisure time. While manuals may attempt to dissuade readers from taking up these other options (many of which have implications for fitness, such as television watching), exercise manuals more generally construct the problem as one of better disciplining or managing the time that one has. An exercise manual by the American Heart Association (AHA), for example, expresses the obstacles to getting fit in terms of time:

You know you should be more physically active. You even want to be. But where will you find the time? And just how active do you have to be? Fitting in Fitness will help you find the answers. ... This Fitting in Fitness handbook is designed to help you get off the sofa and get moving with minimal hassle and maximum results. (American Heart Association, 1997: pp. xiii-xiv) Accordingly, the AHA manual goes on to suggest hundreds of ways to insert aerobic activity into daily life, including taking the dog for a walk, using stairs rather than elevators, and using water jugs for weight-bearing exercises. Similar instructions appear in other manuals, constructing fitness as an individual choice of how to spend one's discretionary time rather than, for example, promoting collective strategies such as exercise breaks during the workday.

An exercise manual by the publisher of Men's Health magazine targets timepressed affluent male readers. The authors attempt to educate their readers in the role of time management for leisure:

The issue [of time for fitness] really boils down to time management - using those 86,400 seconds wisely and efficiently enough each day so that you can spare at least 1,800 of them for exercise. It's a matter of setting priorities. One national survey of men in their thirties and forties found that 67 percent include being healthy and fit in their personal definition of success.... Being in great shape is something that we'd love to do... if we had the time. (Kaufman \& Kirchheimer, 1997: p. 28)

The manual includes several time management suggestions, including laying out your clothes the night before, hiring help for chores to create time for exercise, and waking 
up earlier. Here, the assumed character of the intended class of readers mediates how time is constructed: such lessons apply what is taken as an unproblematic, workoriented notion of time to leisure - not only using time management strategies to carve out time for fitness leisure, but also making one's leisure time more efficient.

In general, exercise manuals suggest a range of techniques for managing leisure time that are in keeping with the Protestant work ethic (Weber, 1992), including scheduling and exercising at the same time each day, using an exercise log and other record-keeping devices, and charting one's progress - all means to 'turn mere behavior into a good habit' (American College of Sports Medicine, 1998: p.17). In another manual geared towards men, readers are encouraged to use time-management skills they already have to insert exercise into their lives:

When you're starting out with a fitness program, self-discipline is often one of your highest hurdles. Many people find that devising a schedule is the easiest way around that. In the beginning, you may want to schedule your workouts at the same time each day....Making specific appointments and keeping them is something you're used to in life. If you can do it for the dentist, you can do it for your sense of well-being. (Levy \& Shafran, 1986: pp. 19-20)

A manual addressing women consumers from the publishers of Self magazine makes the same point, telling readers to make fitness 'dates' (Billings, 1998: p. 42), suggesting how the gender, as well as class, of the assumed reader mediates the construction of fitness as leisure. In these attempts to habituate exercise, the 'new' habit is thus affiliated with already-established habits, such as making and keeping appointments.

As illustrated in the previous examples, the construction of leisure time in the exercise manuals reproduces the primacy given to individual choice and sovereignty within consumer culture, and the ideology of self-responsibility that characterizes this era of individualization (Bauman, 2000; Beck \& Beck-Gernsheim, 2002; Slater, 1997). In such a context, population inactivity (a concern of the AHA, among other institutions) is addressed not through calls for collective solutions, which are likely to be opposed as infringements on individual choice, but through calls to better discipline one's non-work time, which ironically reaffirm the equation in the popular imagination of leisure with freedom and choice. The exercise manuals' lessons in time management are part of a wider move to entrust individuals with the choice of being fit - and thus to hold individuals accountable for a lack of fitness (Ingham, 1985). This underlines the political nature of leisure and leisure time (Rojek, 1989b): the governing of populations in a neo-liberal society relies on the governing of leisure, such that individuals enact their freedom and make choices in keeping with broader social agendas (Barry et al., 1996). The political order requires that the freedom of leisure be productive, and the body-at-leisure be disciplined and predictable (Frank, 1991).

Disciplinary techniques such as scheduling and record-keeping are offered as tools to help readers to exercise. More generally, the 'discipline "makes" individuals' (Foucault, 1977: P. 170), ideally producing a habitual order of behaviours, such as time management and self-scrutiny (as well as physical exercise). For Foucault, the key feature of disciplinary power is that the control of movements, times and spaces (through time keeping, regimentation, record keeping, etc.) not only produces 
competencies (we become good at our exercises) but also a capacity for selfsurveillance. We internalize the disciplinary gaze and thus make it play upon ourselves spontaneously (Foucault, 1977: p. 202), even as, and perhaps because, the experience of such self-surveillance - in the context of leisure - is swathed in connotations of freedom. In an era of individualization, if we are not only free to choose our identity, but are 'obliged to be free,' (Rose, 1996: p. 17), then what could be more effective than to locate the exercise of obligation in the imagined realm of freedom?

\section{Leisure as Self-Investment}

In addition to lessons on better disciplining leisure time, the exercise manuals attempt to overcome the apparent conflict between the work of exercise and its marketing as leisure by promoting a cost-benefit logic: the effort of exercise pays off in terms of cultural, physical and social capital (Bourdieu, 1986). Exercise manuals thus attempt to 'mobilize' the reader (cf. Miller \& Rose, 1997) by connecting the perceived fears and aspirations of the middle class target market (anxiety about the impression made upon others, the desire to promote oneself and be successful in the labour and social marketplaces) with the rewards associated with exercise (better health, confidence, appearance). As with time management, the lesson in leisure as self-investment reinforces a productive logic: leisure time is to be used to produce value - the value of the fit body.

In his assessment of the body in action, Frank (1991: p. 55) suggests that the disciplined body in consumer culture is closely related to the mirroring body, in that successful discipline gives rise to a body that reflects social ideals and mirrors dominant images. The benefits of fitness (the rewards of self-discipline and effective time management) are thus formulated in the dominant terms of consumer body culture - attractiveness, confidence, vitality, charisma. Consider, for example, the following excerpt from a weight training manual:

Weight training helps give you the feeling that you are your body, not just in it.

...Your body is no longer something you drag along or something that holds you back. ... How you look is a basic part of your social identity and as you change and improve the look of your body you will see a change in the attitude of people you come into contact with. These days there aren't many things in life that an individual can control... but you can become the master of your own body.

(Dobbins \& Sprague, 1981: pp. 7-8)

The authors' representation of control as mastery of one's social presenceconfidence in and as a body_recalls Bourdieu's (1984) work on how class and occupation inflect bodily dispositions. This is an example of the role of such texts in reproducing and disseminating popular beliefs and values; in this case, the middle class interest in status, style and the body-for-others (Bourdieu, 1984: p. 213).

Besides improved appearance and confidence, health is also portrayed in the manuals as a pay-off from the self-investment of exercise. Health in Western culture has long been considered an individual responsibility and a natural state (Whorton, 1982), and in a neo-liberal era of entrepreneurial citizens, this translates into a moral imperative for individuals to be responsible for their health and fitness (Crawford, 1980; White, et al., 1995). Ill health (or simply the failure to 'look healthy') is taken 
as a sign of transgressions against nature, serving as a symbol of personal inadequacy. Like self-presentation, a healthy appearance is a form of symbolic capital. In the absence of a healthy appearance, reading an exercise manual or belonging to a health club can, at least, signify one's moral character, demonstrating that one is cognizant of the responsibility of self-care.

Exercise manuals make clear that fitness is a strategic mode of self-investment and offer it as a panacea for all of one's problems:

Fitness, as you know, touches on every aspect of your life. With exercise, you'll:

Look and feel better; Cut your risk of deadly diseases...; Have better sex and even prevent impotence; Meet new people, develop friendships, or maybe even find your future mate; Boost your self-confidence many times over. (Kaufman \& Kirchheimer, 1997: p. 2)

The point, here, is not to discount the physical and mental health benefits of exercise-for which there is compelling scientific evidence (see, for example, Hardman \& Stensel, 2003) - but to highlight how leisure is constructed as the sphere of self-care, in which to attend to all of the problems (potential, real, imagined) of the body and self in contemporary society. In a consumer service economy, looking good and looking healthy bear on one's exchange value (Featherstone, 1982), especially for those in the service class whose stock-in-trade are images and appearances. The consumption of fitness manuals and magazines - and lifestyle and self-improvement guides more broadly - is thus inextricably linked to the increasing cultural emphasis on, and economic value of, the cultivation of self-presentation skills.

The economic pragmatism of self-investment may sit awkwardly with the cultural imaginary of leisure as a time of freedom and relaxation, but leisure scholars will recognize this as indicative of the impossibility of drawing a hard and fast line between work and leisure. Along these lines, Elias and Dunning (1986: pp. 96-8) outlined a 'spare time spectrum', in which discretionary time is used to accomplish a multitude of tasks that fall into three main categories: spare-time routines (such as the routine care of one's self and household); orientation and self-expansion activities (such as volunteer work, hobbies and self-improvement work); and more typical leisure activities (such as socializing, mimetic and play activities). These are not mutually exclusive categories; time-pressed individuals in particular may use 'simultaneous consumption' to combine multiple functions (Chaplin, 1999: p. 45). Thus, mimetic and socializing activities (such as attending a cardio-box class and chatting with friends at a health club) overlap with self-expansion activities (the physical and social capital from the health club used for occupational advancement). What is striking in the exercise manuals is the degree to which the logic of selfexpansion pervades the representation of leisure time: leisure is not so much a category sitting alongside self-expansion activities, as a category overwritten by the logic of self-improvement. One could argue that this is a feature, more generally, of leisure in contemporary consumer economies: the logic of self-investment potentially transforms even banal, routine care activities into vehicles for self-expression and status-positioning, and thus opportunities for profit.

The application of a work ethic to leisure activities has been well documented in leisure research. For example, past research suggests that those with jobs that involve higher levels of autonomy (such as the professional/managerial class) are more likely 
to have an 'extension' pattern to their work-leisure relationship, meaning that work and leisure share at least some common characteristics or style, and that there is no clear demarcation experienced between the two spheres (Parker, 1976). Writing thirty years ago, Parker noted that leisure was becoming more like work, quoting from Stone's earlier analysis: 'more and more we work at our play...we begin to evaluate our leisure in terms of the potential it has for work' (Stone, 1958: p. 285, cited in Parker 1976: p. 70). However, the application of work values to leisure activities, and more generally the treatment of leisure time as a market resource (Rojek, 1989a, 1995), does not necessarily indicate that leisure is simply becoming more like work. Consider, for example, how work is becoming more like leisure, in creative work places (Florida, 2002), in the rise of the workplace nap (Baxter \& Kroll-Smith, 2005), or in the ways in which some aspects of domestic labour (such as cooking and gardening) have taken on a 'more leisurely, discretionary component' (nVision, 2006: p. 3). Normatively conceptualized as separate spheres, leisure and work (like culture and economy; see du Gay \& Pryke, 2002) are mutually produced through material practices, rather than existing as a priori, static categories. The question thus becomes not whether there is a new 'blurring' of leisure and work (as if they were ever wholly separate spheres), but how they are mutually defined at particular historical and social moments. Understandings and experiences of leisure are - and have been since the 'invention' of leisure in early modern Europe (Burke, 1995) - interdependent with the social organization of work and capital. Parker's (1976) findings illustrate how the categories of work and leisure are contextual, shaped by individuals' particular locations in the mode of production.

The marketing of exercise as a panacea and the use of cost-benefit rhetoric encourages participation in fitness as a means to some other end, rather than an end in itself - an instrumental construction of leisure that has implications for the notion of pleasure, as discussed with regard to the third leisure theme.

\section{Consumption, Leisure and Pleasure}

In addition to the naturalization of fitness as leisure, and promoting fitness through its physical and social capital rewards, exercise manuals also represent fitness as a consumer activity. Leisure and consumption are doubly connected: leisure is increasing commodified; and notions of leisure facilitate commodification. That is, on the one hand, leisure time has become increasingly colonized by consumer products and services since the post-war leisure boom; on the other, an affiliation with leisure lends connotations of 'fun, freedom and self-expression' (Harris, 2005: p. 12) to consumer goods and services.

The authors of exercise manuals produce the relatively uniform message that exercise-as-leisure requires consumer goods and services. The endorsement of fitness products is not limited to explicitly consumption-oriented guides, such as the manual from the publishers of Men's Health magazine. In the manuals from both the AHA and American College of Sports Medicine (ACSM), for example, the goal of making physical activity accessible to a general population - through downplaying the necessity of consumer expense-is accompanied by the acknowledgement that fitness products and services are often regarded as an essential part of getting fit: 
We'll say it again: All you need to fit in fitness is a comfortable pair of walking shoes. So why spend money on fitness equipment? In a word, variety. Variety is not only the spice of life, it's what keeps physical activity fun. Boredom, on the other hand, is one of the most common reasons people give for quitting regular exercise. (American Heart Association, 1997: p. 96)

Similarly, the ACSM's manual (1992: p. 102) acknowledges: 'Some people find home exercising lonely or boring and want the variety and socializing that a fitness center can offer.' Fitness educators, producers, and promoters are constrained not only by the tastes of consumers, but also by broader social demands for fun, immediacy, novelty and variety; elements, which if not available in the activities themselves are furnished through the associated fitness products and services.

Consumption also comes into play in the manuals' attempts to motivate readers to maintain their exercise regimes. Indeed, material self-reward has become a standard technique for habituation and motivation in contemporary consumer culture:

Be nice to yourself... Attach an appropriate reward to each of your long-term, short-term and immediate goals. If you lose the 15 pounds over 6 months, buy yourself that watch you've been wanting. ...Sure, it's bribery, but it works. (Schlosberg and Neporent, 1996: p. 28)

The indulgence of shopping is thus made permissible through the discipline of exercise, providing consumers with a formula for negotiating the larger tension in consumer culture between hedonism and discipline. Such 'calculating hedonism' (Jacoby, 1980, cited in Featherstone 1982: p. 18) resolves, at least momentarily, the double-bind of the fitness consumer - to be a 'good body' requires self-discipline; to be a 'good consumer' requires self-gratification. Here, the two obligations are configured as sequential rather than conflicting aspects of the same lifestyle: do two more sit-ups now, buy the wristwatch later.

The fitness industry benefits from endorsements from external fields such as health promotion and physical education, and gains institutional support and scientific legitimacy from non-profit organizations such as the AHA. Nevertheless, health clubs, fitness magazines and other fitness products operate not within the health or medical fields, but within a consumer field, its relative autonomy established through the differences between exercise-as-medicine and exercise-as-leisure. The former may be 'good,' but the latter is 'fun.' Or is it? Fun is spontaneous, immediate, irrational, inconsequential (Ferguson, 1989; Huizinga, 1970). In terms of time use, self-investment rewards, and legitimation of consumer indulgence, however, exercise manuals construct fitness not as fun, but as a rational, instrumental activity, associated with an instrumental notion of pleasure. ${ }^{6}$ Non-instrumental fun has been identified as a key to understanding the social function and individual engagement with forms of leisure (e.g. Elias \& Dunning, 1986; Ferguson, 1989; Maguire, 1992); yet, modernity has been marked by a diminution of this 'play element' in everyday life (Huizinga, 1970). It is this form of fun that is noticeably absent in the exercise manuals.

The predominant construction of pleasure in the sample of exercise manuals is a decidedly narrow one: pleasure is to be found in one's righteous self-discipline and in one's body-for-others - the confidence one gets from a fit body, the impression it 
makes upon others, the chance to shop for it - and not in the exercise activities themselves. Consider the following example from Jane Fonda's Workout Book:

You will always have a good reason to skip your workout. You could be cleaning the house, baking, watching a movie, going straight home from work or sleeping late. But when you make yourself exercise and afterwards feel that tingle through your body, the sense of exhilaration and your own pleasure in your discipline, you'll agree it was worth it. (Fonda, 1981: p. 56)

Even in those instances in which the physical sensation of working out is highlighted as pleasurable (such as Fonda's descriptions of 'the burn'), such corporeal immediacy is yoked to something at-a-distance: the approval of others, reduced health risks, and so forth.

Despite the post-modern aspects of fitness activities (such as the simulation of manual labour through the use of exercise machines; see Glassner, 1989), exercise manuals, at least, remain a resolutely modern form, in which pleasure is privileged over fun. This is not to suggest that fitness activities hold no opportunities for fun, or for 'peak' or 'flow' experiences (Csikszentmihalyi, 1975; see also Maguire, 1992), in which one is so absorbed in the activity that there ceases to be a conscious awareness of a separation of the self from the activity, allowing an enjoyable loss of self. This sort of non-instrumental immediacy remains at the core of the cultural imaginary of leisure in consumer culture-leisure linked not to the function of social control and the instrumental reproduction of the social order, but to the ethos of spontaneity, excitement, play and irrationality (e.g. Dumazedier, 1974; Ferguson, 1989; Rojek, 1995). However, the commercial nature of the fitness field (and leisure more broadly) constrains the ideal construction (and, in a different way, the subjective experience) of the playful aspects of leisure. In a consumer society, the obligation and pleasure of self-work are harnessed as the engine of the economy and social reproduction. Pleasure is instrumentalized, both as a means of motivating individuals to exercise, and as part of the larger reproduction of service economies, consumer cultures and neo-liberal social orders that rely on self-managing, responsible individuals.

\section{Conclusion}

Fitness need not necessarily be associated with leisure. Historically, physical exercise has also been linked with the military, work preparedness, religion and moral character building, and therapeutic health regimes. Moreover, working out does not readily fit with the cultural imaginary of leisure as a time of freedom, relaxation and non-instrumental activity. Commercial fitness thus contains a conflict between the sustained work and discipline of physical exercise and consumer culture's messages of fun and instant results. It is this tension-between notions of work and ideals of leisure - that makes fitness such a fruitful case study of the meaning of leisure in contemporary society.

The commercial health club industry and exercise manual authors reproduce taken-for-granted assumptions about consumers' (and especially professional/managerial consumers') patterns of activity, occupational resources, work ethos, bodily dispositions and general interest in the cultivation of status and appearance. These assumptions mediate how fitness is constructed as an activity 
properly belonging to leisure time, through which work may be done on the body, health and self. The analysis of exercise manuals suggests how the two concepts of leisure and work are mutually constitutive rather than mutually exclusive. The application of a Protestant work ethic to the management of leisure time and investment in appearance- and health-related symbolic capital represent points of convergence between the mentalities and rationalities of the paid-work sphere and discretionary leisure time. Common sense attributes and uses of work and leisure reflect broader social forces and changes: a political-economic system that places emphasis on individual responsibility; a culture of consumption fuelled by promises of individual choice and freedom; and a class structure and mode of production in which some may experience aspects of work (paid and unpaid) as leisurely.

Running parallel with the cultural imaginary of leisure as a time of freedom from work and responsibility is the construction of leisure as a time of freedom to take up the obligation of self-work. This is not a new conception of leisure, but it is one that, over the modern period, has been extended to a wider population. Writing at the turn of the twentieth century, Veblen commented upon the 'work' required of the nouveaux riches to display and defend their new class position. Social mobility required that the gentleman 'change his life of leisure into a more or less arduous application to the business of learning how to live a life of ostensible leisure in a becoming way' (1959: p. 34). In the contemporary era, the individual is faced with the obligation of productive leisure - the arduous task of making oneself 'fit' for a life in a consumer culture and service economy.

Leisure as a time of doing nothing, of idleness, is a refusal of the obligation of productivity and is thus reserved for the very wealthy (for whom it is sanctioned), and tolerated in the very poor (although even the unemployed must show themselves to be actively re-skilling and seeking jobs; Dean, 1995). For the remainder, leisure must be a time for the 'production of value - distinctive value, status value, prestige value' (Baudrillard 1998: p. 157). The commercial fitness field is but one example of the institutional and discursive modes by which individuals are educated in how to yield more value from their available time and corporeal resources.

\section{References}

American College of Sports Medicine. (1992) ACSM Fitness Book (Champaign, IL: Human Kinetics).

American College of Sports Medicine. (1998) ACSM Fitness Book, $2^{\text {nd }}$ Edition (Champaign, IL: Human Kinetics).

American Heart Association. (1997) Fitting in Fitness (New York: Random House). Anderson, W.T. (1971) Identifying the convenience-oriented consumer, Journal of Marketing Research 8(2), pp. 179-83.

Barry, A., Osborne, T. \& N. Rose (Eds.) (1996) Foucault and Political Reason: Liberalism, Neo-Liberalism and Rationalities of Government (Chicago: University of Chicago Press).

Baudrillard, J. (1998) The Consumer Society: Myths and Structures (London: Sage).

Bauman, Z. (2000) Liquid Modernity (Cambridge: Polity).

Bauman, Z. (2004) Identity: Conversations with Benedetto Vecchi (Cambridge: Polity). 
Baxter, V. \& Kroll-Smith, K. (2005) Normalizing the workplace nap: blurring the boundaries between public and private space and time, Current Sociology 53(1), pp. 33-55.

Beck, U. \& Beck-Gernsheim, E. (2002) Individualization: Institutionalized Individualism and its Social and Political Consequences (London: Sage).

Bell, D. \& Hollows, J. (2005) Ordinary Lifestyles: Popular Media, Consumption and Taste (Maidenhead: Open University Press).

Billings, L. (1998) Self's Better Body Book (New York: Condé Nast Books).

Bourdieu, P. (1984) Distinction: A Social Critique of the Judgment of Taste (Cambridge, MA: Harvard University Press).

Bourdieu, P. (1986) The forms of capital, in: J. Richardson (Ed.) Handbook of Theory and Research for the Sociology of Education, pp. 241-58 (New York: Greenwood Press).

Bourdieu, P. (1993) The Field of Cultural Production: Essays on Art and Literature (New York: Columbia University Press).

Boyatzis, R.E. (1998) Transforming Qualitative Information: Thematic Analysis and Code Development (London: Sage).

Bramham, P. (2002) Rojek, the sociological imagination and leisure, Leisure Studies 21, pp. 221-34.

Bureau of Labor Statistics. (2006) Consumer Expenditures in 2004. Available online: http://www.bls.gov/cex/csxann04.pdf (accessed January 2007).

Burke, P. (1995) The invention of leisure in early modern Europe, Past and Present 146, pp. 136-50.

Chaplin, D. (1999) Consuming work/productive leisure: the consumption patterns of second home environments, Leisure Studies 18, pp. 41-55.

Crawford, R. (1980) Healthism and the medicalization of everyday life, International Journal of Health Services 10, pp. 365-88.

Csikszentmihalyi, M. (1975) Beyond Boredom and Anxiety (San Francisco: JosseyBass).

Dean, M. (1995) Governing the unemployed self in an active society, Economy and Society 24(4), pp. 559-83.

Defrance, J. \& Pociello, C. (1993) Structure and evolution of the field of sports in France (1960-1990), International Review for the Sociology of Sport (28), pp. 123.

Dobbins, B. \& Sprague, K. (1981) The Gold's Gym Weight Training Book (New York: Berkley Books).

du Gay, P. \& Pryke, M. (Eds.) (2002) Cultural Economy: Cultural Analysis and Commercial Life (London: Sage).

Dumazedier, J. (1974) Sociology of Leisure (Amsterdam: Elsevier).

Eide, M. \& Knight, G. (1999) Public/private service: service journalism and the problems of everyday life, European Journal of Communication 14(4), pp. 525547.

Elias, N. \& Dunning, E. (1986) Quest for Excitement: Sport and Leisure in the Civilizing Process (Oxford: Blackwell).

Esteve, R., San Martín, J. \& López, A.E. (1999) Grasping the meaning of leisure: developing a self-report measurement tool, Leisure Studies 18: pp. 79-91. 
Euromonitor. (2001) Sports Equipment in the USA. Euromonitor Global Market Information Database. Available online: http://www.euromonitor.com (accessed March 2002).

Featherstone, M. (1982) The body in consumer culture, Theory, Culture \& Society 2(1), pp. 18-33.

Fereday, J. \& Muir-Cochrane, E. (2006). Demonstrating rigor using thematic analysis: a hybrid approach of inductive and deductive coding and theme development, International Journal of Qualitative Methods 5(1): pp. 1-11.

Ferguson, H. (1989) Sigmund Freud and the pursuit of pleasure, in: C. Rojek (Ed.) Leisure for Leisure: Critical Essays, pp. 53-74 (London: Macmillan).

Ferguson, P.P. (1998) A cultural field in the making: gastronomy in $19^{\text {th }}$-century France, The American Journal of Sociology 104(3), pp. 597-641.

Florida, R. (2002) The Rise of the Creative Class (New York: Basic Books).

Fonda, J. (1981) Jane Fonda's Workout Book (New York: Simon and Schuster). Foucault, M. (1977) Discipline and Punish: The Birth of the Prison (New York: Vintage Books).

Foucault, M. (1991) Questions of method, in: G. Burchell, C. Gordon \& P. Miller (Eds.) The Foucault Effect: Studies in Governmentality, pp. 73-86 (Chicago: University of Chicago Press).

Frank, A. (1991) For a sociology of the body: an analytical review, in: M. Featherstone, M. Hepworth \& B.S. Turner (Eds.) The Body: Social Process and Cultural Theory, pp. 36-102 (London: Sage).

Gershuny, J. (2000) Changing Times: Work and Leisure in Postindustrial Society (Oxford: Oxford University Press).

Giddens, A. (1991) Modernity and Self-Identity (Cambridge: Polity).

Glaser, B.G. and Strauss, A.L. (1967) The Discovery of Grounded Theory: Strategies for Qualitative Research (New York: Aldine).

Glassner, B. (1989) Fitness and the postmodern self, Journal of Health and Social Behavior 30, pp. 180-91.

Green, H. (1986) Fit for America: Health, Fitness, Sport and American Society (New York: Pantheon Books).

Hardman, A. \& Stensel, D. (2003) Physical Activity and Health: The Evidence Explained (London: Routledge).

Hargeaves, J. (1986) Sport, Power and Culture: A Social and Historical Analysis of Popular Sports in Britain (New York: St. Martin's Press).

Harris, D. (2005) Key Concepts in Leisure Studies (London: Sage).

Haworth, J. \& Lewis, S. (2005) Work, leisure and well-being, British Journal of Guidance \& Counselling 33(1), pp. 67-79.

Hogenraad, R., McKenzie, D.P. \& Péladeau, N. (2003) Force and influence in content analysis: the production of new social knowledge, Quality and Quantity 37, pp. 221-38.

Howell, J. \& Ingham, A. (2001) From social problem to personal issue: the language of lifestyle, Cultural Studies 15(2), pp. 326-351.

Huizinga, J. (1970) Homo Ludens: A Study of the Play Element in Culture (London: Temple Smith). 
Ingham, A.G. (1985) From public issue to personal trouble: well-being and the fiscal crisis of the state, Sociology of Sport Journal 2(1), pp. 43-55.

Ingraham, C. (1994) The heterosexual imaginary: feminist sociology and theories of gender, Sociological Theory 12(2), pp. 203-19.

Jacobs, J.A. \& Gerson, K. (1998) Who are the overworked Americans?, Review of Social Economy 56(4), pp. 442-59.

Jacoby, R. (1980) Narcissism and the crisis of capitalism, Telos 44, pp. 60-71.

Jenkins, R. (1992) Pierre Bourdieu (London: Routledge).

Kaufman, B.P. \& Kirchheimer, S. (1997) Stronger Faster: Workday Workouts That Build Maximum Muscle in Minimum Time (Emmaus, PA: Rodale Press, Inc).

King, N. (2004) Using templates in the thematic analysis of text, in: C. Cassell \& G. Symon (Eds.) Essential Guide to Qualitative Methods in Organizational Research, pp. 256-70 (London: Sage).

Laberge, S. \& Kay, J. (2002) Pierre Bourdieu's sociocultural theory and sport practice, in: J. Maguire \& K. Young (Eds.) Theory, Sport \& Society, pp. 239-66 (Oxford: JAI, Elsevier Science).

Levy, M.Z. \& Shafran, J. (1986) Gym Psych: The Insider's Guide to Health Clubs (New York: Fawcett Columbine).

Lewis, S. (2003) The integration of paid work and the rest of life. Is post-industrial work the new leisure?, Leisure Studies 22, pp. 343-55.

McCarthy, J. (1987) An industry in transition, Athletic Business 11(4), pp. 40-46.

McGee, M. (2005) Self-Help, Inc.: Makeover Culture in American Life (New York: Oxford University Press).

Maguire, J. (1992) Towards a sociological theory of sport and the emotions: a process-sociological perspective, in: E. Dunning \& C. Rojek (Eds.) Sport and Leisure in the Civilizing Process: Critique and Counter-Critique, pp. 96-120 (London: Macmillan).

Miller, P. \& Rose, N. (1997) Mobilizing the consumer: assembling the subject of consumption, Theory, Culture \& Society 14(1), pp. 1-36.

Mintel. (2004) Sports Goods Retailing-UK, March (Mintel Marketing Intelligence).

Mintel. (2006) Leisure Time-UK, February (Mintel Marketing Intelligence).

Morris, V. (1997) President of Crunch gym chain mixes fitness with fun. Transcript of interview with Doug Levine, on: CNNfn (Cable News Network Financial), Business Unusual, 18 July (Federal Document Clearing House, Inc).

Mrozek, D.J. (1989) Sport in American life: from national health to personal fulfillment, 1890-1940, in: K. Grover (Ed.) Fitness in American Culture: Images of Health, Sport, and the Body, 1830-1940, pp. 18-46 (Amherst, MA: University of Massachusetts Press).

nVision. (2005) The Leisure Society: Executive Summary (London: The Future Foundation).

nVision. (2006) A Life of Leisure: Executive Summary (London: The Future Foundation).

Parker, S. (1976) The Sociology of Leisure (London: George Allen \& Unwin). Rojek, C. (1985) Capitalism \& Leisure Theory (London: Tavistock Publications).

Rojek, C. (1989a) Leisure and 'the ruins of the bourgeois world', in: C. Rojek (Ed.) Leisure for Leisure: Critical Essays, pp. 92-112 (London: Macmillan). 
Rojek, C. (1989b) Leisure time and leisure space, in: C. Rojek (Ed.) Leisure for Leisure: Critical Essays, pp. 191-204 (London: Macmillan).

Rojek, C. (1995) Decentring Leisure: Rethinking Leisure Theory (London: Sage).

Rose, N. (1996) Inventing our Selves: Psychology, Power, and Personhood (Cambridge: Cambridge University Press).

Schlosberg, S. \& Neporent, L. (1996) Fitness for Dummies (Foster City, CA: IDG Books).

Simmel, G. (1950) Secrecy, in: K.H. Wolff (Ed.) The Sociology of Georg Simmel, pp. 330-44 (New York: The Free Press).

Slater, D. (1997) Consumer Culture and Modernity (Cambridge: Polity).

Smith Maguire, J. (2002) Body lessons: fitness publishing and the cultural production of the fitness consumer, International Review for the Sociology of Sport 37(3/4), pp. 449-64.

Smith Maguire, J. (2006) Exercising control: empowerment and the fitness discourse, in: L.K. Fuller (Ed.) Sport, Rhetoric, and Gender: Historical Perspectives and Media Representations, pp. 119-29 (New York: Palgrave).

Smith Maguire, J. (2008) Fit for Consumption: Bodies, Status and the Fitness Field (London: Routledge).

Stone, G. (1958) American sports: play and display, in: E. Larrabee \& R. Meyersohn (Eds.) Mass Leisure, pp. 253-64 (Glencoe, IL: The Free Press).

Swann, C. (2006) GDP and the economy: October 2006. US Department of Commerce Bureau of Economic Analysis. Available online: http://www.bea.gov/scb/pdf/2006/10October/gdp_economy.pdf (accessed May 2007).

Veblen, T. (1959) The Theory of the Leisure Class: An Economic Study of Institutions (New York: The Viking Press).

Weber, M. (1992) The Protestant Ethic and the Spirit of Capitalism (London: Routledge).

White, P., Young, K. \& Gillett, J. (1995) Bodywork as a moral imperative: some critical notes on health and fitness, Society and Leisure 18, pp. 159-82.

Whorton, J.C. (1982) Crusaders for Fitness: The History of American Health Reformers (Princeton, NJ: Princeton University Press).

Zuzanek, J., Beckers, T \& Peters, P. (1998) The 'harried leisure class' revisited: Dutch and Canadian trends in the use of time from the 1970s to the 1990s, Leisure Studies 17, pp. 1-19.

\section{Endnotes}

${ }^{1}$ Data taken from the International Health Racquet and Sportsclub Association (IHRSA) website (http://cms.ihrsa.org/IHRSA/viewPage.cfm?pageId=149; accessed March 2005). 
${ }^{2}$ Data taken from the IHRSA website (http://cms.ihrsa.org/IHRSA/viewPage.cfm?pageId=978; accessed March 2007). ${ }^{3}$ According to the IHRSA website (http://cms.ihrsa.org/IHRSA/viewPage.cfm?pageId=808; accessed January 2007), half of all US commercial health club members make more than $\$ 75,000$ annually, whereas only about the top 20 per cent of the general population makes that amount (see Bureau of Labor Statistics, 2006). Similarly, fitness magazine media kits show that more than a third of readers are professional/managerial workers (Smith Maguire, 2008).

${ }^{4}$ The proportion of commercial health clubs to YMCAs is based on a 2005 count of 29,069 commercial clubs (from the IHRSA website, http://cms.ihrsa.org/IHRSA/viewPage.cfm?pageId=804; accessed January 2007) and 2,617 YMCAs (from the YMCA website, http://www.ymca.net; accessed January 2007).

${ }^{5}$ The sample was composed of five exercise manuals from the health-educationorientation (the American College of Sports Medicine's ACSM Fitness Book (1992 and 1998 editions), American Heart Association's Fitting in Fitness (1997), and Fitness Facts (1989) and its $19992^{\text {nd }}$ Edition, The Health Fitness Handbook), and eight from the more commercially-oriented perspective (The Gold's Gym Weight Training Book (1978), Jane Fonda's Workout Book(1981), Nautilus Fitness for Women (1983), Gym Psych (1986), Fitness for Dummies (1996 and 2000 editions), Stronger Faster (from the publishers of Men's Health magazine, 1997), and Self magazine’s 1998 Self's Better Body Book). 
6 'Fun' and 'pleasure' are used interchangeably in popular discourse (and the cultural imaginary of leisure); even in academic literature the terms are often confused.

Regardless of the terms used by individual authors, the key distinguishing feature is the degree of instrumentality: is the leisure form pursued as an end in itself, or is it pursued as a means to some other end? 